УДК 177.7

DOI: 10.18101/1994-0866-2019-2-89-95

\title{
ВЗАИМОДЕЙСТВИЕ ВРАЧА И ПАЦИЕНТА: СОЦИОКУЛЬТУРНЫЙ АНАЛИЗ
}

\author{
(C) Камалиева Ирина Ринатовна \\ кандидат философских наук, доцент, \\ Южно-Уральский государственный университет (НИУ) \\ Россия, 454080, г. Челябинск, пр. Ленина, 76 \\ E-mail: irina.kamalieva@yandex.ru
}

Статья содержит социально-культурный анализ проблем взаимодействия врача и пациента в современной медицине. По мнению автора, сострадание к пациенту со стороны врача в современной медицине сменилось биологизаторскими, корпоративнотехнократическими и биополитическими ориентирами, имеющими многовековую историю развития и сформированными несколькими взаимосвязанными между собой социокультурными факторами, возникшими последовательно в процессе развития медицинской науки. Автор считает, что современной медицине характерны следующие явления, свидетельствующие о смене ее ценностных парадигм: утрата универсальных, действовавших до начала XX в. гуманистических этических установок; «размывание» целостного образа пациента вследствие оперативных и психофармакологических вмешательств, прогресса медицинских технологий и техники; снижение уровня доверия к врачу со стороны пациента ввиду исторически обусловленной закрытости и субкультуризации медицинского сообщества, а также дробление специализации врачей. В результате проведенного анализа проблемы несоответствия возможностей современной медицины удовлетворить социальный запрос в гуманном отношении к страдающей в болезни личности пациента автор приходит к выводу, что решение проблемы взаимодействия врача и пациента в современных условиях возможно только при экзистенциальном подходе.

Ключевые слова: медицина; врач; пациент; коммуникация; врачебная этика; биоэтика; экзистенциальный подход; доверие; сострадание; взаимодействие.

Для цитирования:

Камалиева И. Р. Взаимодействие врача и пациента: социокультурный анализ // Вестник Бурятского государственного университета. Философия. 2019. Вып. 2. С. 89-95.

Медицина является уникальным социокультурным феноменом, традиционно предполагающим взаимодействие людей на основе доверия со стороны пациента и ожидаемого им сострадательного отношения со стороны врача, приобретающего в условиях научно-технического прогресса и медикализации культуры все большую власть над жизнью и здоровьем больного человека. «Любовь к нашей науке нераздельна с любовью к человечеству», - говорил Гиппократ ${ }^{1}$.

В то же время сегодняшняя медицина формирует необходимые для деятельности врача знания на основе изучения им естественных наук, являясь единственной прикладной сферой деятельности, в которой и субъектом, и объектом нарушения целостности организма является человек. В условиях ожидания гу-

${ }^{1}$ История медицины. Энциклопедия. Знаменитые врачи. Проект кафедры истории медицины Московского государственного медико-стоматологического университета им. А. И. Евдокимова. М., 2016. С. 20. 
манности и милосердия в ответ на доверие со стороны пациента и предоставления взамен врачом научного знания неизбежно «возникает напряжение, рассогласование между естественнонаучной и гуманистической составляющей в медицинском опыте» [3, с. 3], формирующее философско-этическое проблемное поле современной медицины.

Гуманизм медицины античного целителя, врача и философа Гиппократа, объединившего все древнегреческие медицинские школы общей парадигмой рациональной медицины, заключался именно в том, что врач самоотверженно служил каждому больному человеку независимо от его социального положения и материального достатка. Объектом врачебной деятельности был целостный человек. При лечении больного врач не ориентировался только на физиологические сбои в организме, а учитывал и душевные аспекты переживания болезни - страх, стыд и т. д., что способствовало возникновению традиционной медицинской этики.

Медицина вплоть до XVIII в. предполагала индивидуальную деятельность врача, имеющего доступ в дом и жизнь человека, о чем свидетельствуют следующие слова Клятвы Гиппократа: «В какой бы дом я ни вошел, я войду туда для пользы больного, будучи далек от всякого намеренного, неправедного и пагубного, особенно от любовных дел с женщинами и мужчинами, свободными и рабами» [6, с. 87-88]. Дальнейшая институционализация медицины, в первую очередь в результате возникновения военных госпиталей во время Великой французской революции, предполагающих лечение больного человека вне дома, семьи и привычной жизни, способствовала формированию иных профессиональных и этических принципов, накоплению научного медицинского опыта в процессе обмена информацией внутри сообщества и обучению на медицинских кафедрах, началу становления закрытой корпоративной медицинской культуры.

Однако именно идеи Гиппократа через века также породили и противоречия в медицинской практике. М. Фуко в «Рождении клиники. Археология врачебного взгляда» пишет: «На заре человечества, до всех напрасных верований, до всех систем, медицина в своей целостности существовала в непосредственной связи со страданиями, которые она облегчала. Эта связь происходила скорее от инстинкта и восприимчивости, чем от опыта; она устанавливалась индивидом от себя самого к себе самому, до того, как быть включенной в социальную сеть» [9, с. 94]. Именно Гиппократ, по мнению Фуко, «был и последним свидетелем, и наиболее двусмысленным представителем» открытости медицины обществу, когда «медицинский опыт умел находить равновесие между наблюдением и знанием, предохранявшим его от ошибки». Именно Гиппократ, сведший медицину в систему, как утверждает Фуко, способствовал развитию ее закрытости от общества. Философ считал «золотым веком медицины» период до трансформации ее в научное знание, эпоху, в которой она еще сохраняла универсальный способ отношения человечества к самому себе - до введения в нее письменности и секретности. То есть именно клятва Гиппократа стала предпосылкой для возникновения неоднозначно трактуемой современной биоэтикой врачебной тайны, о чем свидетельствуют следующие ее слова: «...устные уроки и все остальное в учении сообщать своим сыновьям, сыновьям своего учителя и ученикам, связанным обязательством и клятвой по закону медицинскому, но никому другому» [6, с. 8788]. Наличие врачебной тайны привело к востребованному институтами власти 
манипулированию врачами информацией о «достойных» и «недостойных» заболеваниях в зависимости от запросов культуры. Психиатрия также до сегодняшнего дня имеет масштабные возможности для влияния на социально-правовой статус человека путем сокрытия или оглашения данных о постановке человека на психиатрический учет.

Возможность патологоанатомического исследования человеческого тела, дающего представление о причинах смерти, и развитие науки сместили приоритет врачебной деятельности с гуманистического на естественно-научный, о чем писал еще М. Фуко: «Вся темная изнанка тела, что ткалась в долгих, непроверяемых глазом фантазиях, разом оказалась оспоренной в своей объективности редукционистским дискурсом врача, и стала рассматриваться его позитивным взглядом как объект.... Все возможности воображаемого пространства, в котором происходило общение врачей, физиологов и практиков... не исчезли, а скорее были перемещены или ограничены особенностями больного, областью "субъективных симптомов", определявшейся для врача уже не как способ познания, но как мир объектов познания» [9, с. 10].

Дальнейший научный прогресс привел к развитию медицинских методов, позволяющих при лечении человека нарушать его телесную целостность хирургическим вмешательством, а в медицине конца XIX - начала XX в. и постоянным присутствием в организме пациента чужеродных материалов за счет развития трансфузиологии, трансплантологии и психофармакологии. Развитие биотехнологий в XX-XXI вв. привело к признанию медициной организма человека как трансформного объекта деятельности, что способствовало «размыванию» образа пациента для врача. В 70-80-е гг. прошлого столетия личность пациента для врача также затмили техника и технологии, позволяющие исследовать организм больного человека. Прогрессирующее развитие современных медицинских технологий и техники, стремительно внедряющихся в повседневную врачебную практику, делает практически невозможным дифференцировать в современном враче-технологе сострадательного лекаря или целителя (каким было его первоначальное предназначение у истоков медицины), потому как субъективные, личностные переживания пациентом болезни являются менее информативными относительно объективных данных медицинских исследований.

Современная закрытость медицины от общества обусловлена также и наличием «собственного языка», т. е. возникновением в античности и дальнейшим развитием древнегреческой и латинской, активно используемой в современной медицине, терминологии [4, с. 3], которая в основном и определяет границы медицинской культуры, превращая ее в закрытую профессиональную субкультуру, регулируемую на сегодняшний день специфическими отраслевыми правовыми и этическими кодексами. Согласно определению А. М. Мясоедова, «медицинская субкультура - система ценностей, идеалов, норм и образцов поведения медицинских работников, их мировоззрение, а также символы, традиции, обычаи, составляющие в совокупности своеобразный, отличный образ жизни, детерминированный спецификой профессиональной медицинской деятельности» [5, с. 9].

Доверие к конкретному врачу снижается и в связи с прогрессирующим дроблением врачебной профессии на множество специальностей, формирующих специфическое мировоззрение врача каждой из них, уводящее от восприятия врачом больного как единого целого - пациента и болезни, которую необходимо лечить 
вместе с самим человеком, т. е. нарушается принцип «лечить больного, а не болезнь». Наличие в арсенале врача специального научного знания, «растворенного» в клинических дисциплинах биохимии, этиологии, патогенеза заболеваний и пр., обозначенных в основном латинской терминологией и сложно адаптируемых к обыденной коммуникации, также препятствует равноценному общению врача и пациента.

В вышеназванных условиях актуализируется проблема противостояния «врач - пациент», своеобразного социального конфликта, вышедшего по содержанию за рамки изначально определенной, специальной сферы отношений. И хотя в отношении врача и пациента изначально нет равноценности сторон, сегодня в этом возникает необходимость в связи с ростом влияния медицины на культуру - именно в связи с возникающей необходимостью в равноправном общении мы и наблюдаем рост социальной напряженности, который привел к возникновению биоэтической (контрактной, по большей части правовой) модели коммуникации в медицине на основе равноправного (в идеале) сотрудничества, в которой одним из основных является принцип «информированного согласия», когда пациенту сообщается вся информация о заболевании и все возможные осложнения при вмешательстве в его организм.

Таким образом, условиями, влияющими на взаимодействие современного врача и пациента, являются: утрата универсальных, действовавших до начала XX в. Гуманистических этических установок; «размывание» целостного образа пациента вследствие оперативных и психофармакологических вмешательств, прогресса медицинских технологий и техники; снижение уровня доверия к врачу со стороны пациента ввиду исторически обусловленной закрытости и субкультуризации медицинского сообщества, а также дробление специализации врачей.

Современная медицина предполагает две модели взаимодействия врача и пациента - патерналистскую и контрактную. В условиях реальной медицины происходит смешение двух моделей, что также способствует непониманию между врачом и пациентом - пациент зачастую не готов принять на себя ответственность за свое здоровье и может расценить действия врача, подразумевающего и участие пациента в лечении, как невнимательность к собственной личности. Данная субъективная оценка пациентом профессиональной модели поведения врача также вызывает напряжение в коммуникации «врач - пациент», накладывая на врача дополнительную ответственность за восстановление социального статуса больного, которая обусловлена исторически: «сталкиваясь с болезнью... больной издревле обращается к врачу за избавлением, покровительством, исцелением. Он просит медика как доктора (знающего), врача (увещевающего больного и заговаривающего болезнь) стать целителем, то есть сделать вновь целым личность, разбитую болезнью на "до" и "после"... Задача возвращения больному такой полноценности ложится на плечи врача...» [10, с. 261].

Разрешением проблемы взаимодействия врача и пациента занимается ряд современных исследователей. Например, проблема недоверия к врачу со стороны пациента отмечена в исследовании Г. Г. Хубулавы: «Больной перекладывает на знающего врача заботу о своем здоровье, но при этом испытывает страх перед врачебным знанием и той властью, которой врач обладает не столько над его болезнью, сколько над его беззащитной личностью» [10, с. 3]. Автор считает возможным разрешить проблему коммуникации врача и пациента, применив аксио- 
логический подход, т. е. «путем введения в исследование онтологической и экзистенциальной константы ценности человеческой жизни, равно соотносимой как с образом врача, так и с образом пациента» $[10$, с. 3$]$.

В биоэтике - учении о нравственной стороне деятельности человека в медицине и биологии - видит выход И. В. Силуянова. В книге «Избранные. Призвание врача» автор пишет: «Медицина - это социальное естествознание. Социально-нравственная составляющая медицинского знания - это тот стержень, который лежит в основе врачебной практики. Важно, чтобы роль биомедицинской этики как регулятора отношений между врачом и пациентом, как элемента, определяющего качество медицинской помощи, как формы защиты личности врача от деструктивных факторов профессии возрастала в современном обществе» $[8$, с. 223-224].

Существуют и критические взгляды на эффективность принципов биоэтики как регулятора врачебной деятельности в условиях современной научной медицины. Например, Н. В. Сергеева отмечает проблему смещения приоритетов современной медицины (в условиях преимущественного регулирования биоэтикой врачебной деонтологии) с аксиологических на формализованные в условиях институализации биоэтики. По мнению исследователя, последняя трансформировалась в нормативную дисциплину, а ее общекультурное содержание при этом элиминировалось в результате постепенной подмены первоначально заданной цели, предполагающей поддержание гармоничного существования природы и культуры, на решение проблем частных отраслей современной медицины - эвтаназии, трансплантологии, репродуктологии и т. п. Что привело к редуцированию принципов в нормы, а признание основополагающих ценностей медицины - сопереживания, альтруизма - сменилось следованием своду формальных правил, регулируемых нормативно-правовыми кодексами [7, с. 3-4]. Таким образом, Н. В. Сергеева ставит под сомнение позицию о всеобъемлющем охвате философско-этических проблем врачебной деятельности принципами биомедицинской этики.

Далее, автор отмечает возникновение политико-правовой ориентированности биоэтического регулирования моральных принципов врачебной практики: «результатом этого процесса [институализации биоэтики] стали серьезные затруднения в этическом осмыслении многих принципиальных вопросов, таких как отношение к патернализму в медицине, смысл и понимание принципов уважения автономии пациента и принципа справедливости при оказании медицинской помощи и др.» [7, с. 3-4].

Как показывает практика, ни биоэтика с ее основным принципом информированного согласия, призванным сохранить достоинство пациента и оградить личность врача от чрезмерного этического давления, ни традиционные медицинская этика и деонтология не в состоянии эффективно регулировать взаимодействие врача и пациента в условиях современной медикализирующейся культуры, когда «медицина обретает новые функции и расширяет зону влияния... принимает участие в формировании индивида по культурным запросам» $[11$, с. 3$]$, уровень недовольства медициной возрастает, количество исков со стороны пациентов к врачам увеличиваются.

Очевидно, что трансформация современной медицинской этики как технократической корпоративной в формализованные правовые отношения обуслов- 
лена общекультурными тенденциями, а гуманистическое мировоззрение врача сменяется технократическим, также следуя им. В связи с этим биоэтика сегодня не в состоянии удовлетворить запросы в гуманном взаимодействии врача и пациента и является скорее этико-правовым корпоративным кодексом.

Однако современный пациент не стал «бездушным» механизмом, каждый сбой в котором может устранить только специальная область естественных или общественных наук, ответственная за его телесное, психологическое или правовое благополучие. Он остался тем же самым «страдающим в болезни существом». В своем труде «О призвании врача» И. А. Ильин отмечает уникальность и необходимость в индивидуальной ориентированности каждого лечебного процесса, утверждая об отсутствии в мире двух одинаковых людей: «Это только в учебниках говорится о «болезнях» вообще и «симптомах» вообще; в действительной жизни есть только «больные в частности», т. е. индивидуальные организмы (утратившие свое равновесие) и страдающие люди» [1, с. 15-16]. В связи с этим только «вчувствование» в состояние больного человека, способность разглядеть индивидуальное своеобразие переживания им болезни автор признает единственно верным для выздоровления пациента способом взаимодействия. Данная позиция в признании уникальности каждого пациента в переживании им болезни, с которой он становится единым целым, сходна с идеей экзистенциализма, признающего уникальность и важность человека, его самоценность даже при очевидности смертельного исхода. Еще во «Всеобщей психопатологии» Ясперс проанализировал проблемы и трудности коммуникации врача и больного и пришел к выводу о том, что «наилучший вид их общения - экзистенциальный: врач подходит к больному не как к объекту манипуляции, а как к личности с неповторимой судьбой» [2, с. 226].

Современный пациент, приобретший к XXI в. помимо физических и душевных недугов еще и экзистенциально-антропологические проблемы, отражением которых является рост числа стран с признанной законодательно эвтаназией, нуждается в гораздо большей человечности, чем больной человек прежних эпох. А медицина, философская составляющая которой уступила место биоэтике, вынужденно делегирует свои функции праву. Однако этико-правововые кодексы не в состоянии разрешить страдания человека непосредственно в состоянии болезни и боли - пациент обречен надеяться на врача. Учитывая патернализм медицины и наличие знаний у врача, недоступных пациенту, результативное взаимодействие в медицине, направленное на возвращение здоровья больному человеку, реализуемо только при доверии со стороны пациента и состраданием к нему со стороны врача, что возможно только при экзистенциальном подходе к решению проблемы.

\section{Лuтература}

1. Ильин И. А. Собр. соч.: в 10 т. Т. 3. Путь к очевидности. О призвании врача. М.: Русская книга, 1994. 592 с.

2. Мотрошилова Н. В. История философии: Запад - Россия - Восток (Кн. 4. Философия ХХ в.). М.: «Греко-латинский кабинет» Ю. А. Шичалина, 1999. 448 с.

3. Кириленко Е. И. Медицина как феномен культуры: опыт гуманитарного исследования: автореф. дис. ... д-ра филос. наук / Томский государственный университет. Томск, 2009. $43 \mathrm{c}$. 
4. Мусохранова М. Б. Терминогенез медицины как социально-философская проблема: автореф. ... д-ра филос. наук / Омский государственный университет им. Ф. М. Достоевского. Омск, 2012. 42 с.

5. Мясоедов А. М. Медицинская субкультура: специфика, структура, динамика: автореф. ... канд. культурологии / Белорусский государственный университет культуры и искусств. Минск, 2012. 29 с.

6. Руднева В. И. Гиппократ. Избранные книги: пер. с лат. М., 1994. 420 с.

7. Сергеева Н. В. Биоэтика как культурный комплекс: автореф. ... д-ра филос. наук / Волгоградский государственный университет. Волгоград, 2010. 50 с.

8. Силуянова И. В. Избранные. О призвании врача. М.: Форма Т, 2008. 257 с.

9. Фуко М. Рождение клиники / пер. с фр., науч. ред. и пред. А. Ш. Тхостова. М.: Смысл, 1998.310 с.

10. Хубулава Г. Г. Философско-антропологический анализ коммуникации врача и пациента: дис. ... д-ра филос. наук / Санкт-Петербургский государственный университет. СПб., 2016. 309 с.

11. Шестерикова О. А. Трансформация медицинского дискурса в современной европейской культуре: дис. ... канд. филос. наук / Санкт-Петербургский государственный университет. СПб., 2014. 24 с.

\title{
DOCTOR-PATIENT INTERACTION: A SOCIO-CULTURAL ANALYSIS
}

\author{
Irina R. Kamalieva \\ Cand. Sci. (Philos.), A/Prof., \\ South Ural State University (National Research University) \\ 4 Lenina Prospect, Chelyabinsk 454080, Russia \\ E-mail: irina.kamalieva@yandex.ru
}

The article presents a socio-cultural analysis of the problems of doctor-patient interaction in modern health service. In our opinion, compassion to patients in modern medicine has been replaced by biologizing, corporate-technocratic and biopolitical landmarks, which are a result of several interrelated sociocultural factors that have arisen consistently in the development of medical science. We believe that modern medicine is characterized by the following phenomena, indicating a change in its value paradigms: the loss of universal, humanistic ethical attitudes that was in force until the beginning of the $20^{\text {th }}$ century; "blurring" of the patient's holistic image as a result of operational and psychopharmacological interventions, progress in medical technology and equipment; a decrease of trust to physicians, which was historically determined by closeness and subculturalization of the medical community, as well as by a progressive subspecialty of doctors. In the light of incompatibility of modern medicine with a social demand in a humane attitude towards a person suffering from a disease the problem of doctor-patient interaction can be solved only with an existential approach.

Keywords: medicine; doctor; patient; communication; medical ethics; bioethics; existential approach; trust; compassion; interaction. 